\title{
Solution Orientated Learning to build resilience in mental health nursing students and recently qualified nurses
}

\section{Introduction}

Resilience has been identified as a key factor for both students' and qualified nurses' capacity to withstand challenges and succeed in their roles (Brennan 2017). It is associated with resourcefulness, calmness, adaptability and confidence. Conversely, lack of resilience is associated with 'burnout' which in turn is a risk factor for intention to leave the profession (Royal College of Nursing (RCN) 2012). In this article we outline how a Solution Orientated Learning (SOL) teaching strategy is used in a Mental Health Nursing pre-registration programme and argue for its potential to contribute to resilience-enhancing outcomes for individuals and services. Resilience comprises multi-dimensional personal characteristics which can be developed (Brennan 2017) and SOL outcomes (with aligned teaching and assessment (Biggs and Tang 2011)) focused on resilience could improve student nurses' current well-being and sustain them post-qualification, thus aiding retention.

'Solution Orientated Learning' refers to a teaching strategy that has grown from the philosophy and approach of Solution Focused Brief Therapy (SFBT) developed by de Shazer and colleagues (Shennan 2014, Milner and Myers 2017). SFBT is a goal orientated, structured therapeutic intervention, in which the therapist works with the client to build on existing strengths to work towards desired outcomes. The focus is less on analysing the causes of the problem and more on what the ideal outcome would be and the steps to achieve this (Milner and Myers 2017). A solution focused orientation has better outcomes than a focus on problems (Braunstein and Grant 2016) perhaps because of the empowerment implied in giving attention and positive reinforcement to the client's own ability to cope with difficulties (or resilience) and build on this.

We propose a new model of learning through a focus on solutions, in which the nurse (both as an individual and a team member) is identified as part of the context and the solution to the challenges of professional practice. As nurse educators working with student mental 
health nurses, we incorporate a solution focused approach that harnesses students' own strengths as they learn. This approach leads to student ownership of their development and builds intrinsic motivation. In working together to plan for solutions, students need to evaluate not only how they respond to service users, family carers and multi-disciplinary colleagues, but also their own strengths, strategies and development needs. Being recipients of a person-centred, solution orientated teaching style is empowering - students absorb the stages and interventions of SFBT which they can use to develop their own learning and use in supporting each other, when leading teams in practice and when working with clients in practice.

\section{Background}

Nurses are responding to frailer and more dependent patients, limited resources and understaffing (Royal College of Nursing (RCN) 2012). These stressors have implications for nurses' mental and physical health and the quality of care offered to service-users. Nurses may find they cannot deliver care to the standard they wish and be concerned about levels of risk to their patients (Cummings 2011). Unhappiness at work leads to high attrition rates (Good Governance Institute 2015) and newly qualified nurses experience high levels of stress and burnout (Health Education England (HEE) 2014) with resultant intention to leave or actual withdrawal from nursing (Brennan 2017). Nurse turnover is damaging for the nurses who leave and for their remaining colleagues, it has negative implications for patient experiences and is costly for organisations (HEE 2014).

Recent reports have highlighted ongoing concerns about students' mental health (Brown 2016, UNITE 2016). Poor student mental health is associated with failing to complete the course, hazardous drinking and suicide (Brown 2016). Patterns of poor mental health among healthcare workers are repeated internationally; Carod-Artal and Vazquez-Cabrera (2013) identify global studies which echo UK and European findings of high levels of emotional exhaustion and depersonalisation with low levels of personal accomplishment. Educators' duty towards the well-being of our students not only applies while they are studying but also 
involves preparation for their professional well-being, with implications for their future retention within the profession.

There are ethical considerations to promoting resilience and we are not suggesting that nurses should be prepared to be ever-more resilient to be able to cope with ever higher demands. Instead, we suggest that resilience should incorporate professional self-respect and assertiveness, empowering nurses to articulate the conditions required for high standards of care, and that skills to support resilience can be embedded throughout the curriculum.

\section{Solution Orientated Learning (SOL) teaching strategies}

Our roles involve teaching pre-registration mental health nurses about the recovery model and nursing responses to meeting the needs of adults with serious mental health problems and dementia. In addition, we prepare students for the transition to post-qualification. Our students express fears about maintaining their values and commitment, knowing that their mentors were in their positions only a few years previously. The SOL approach is aimed at building resilience for individual well-being, culture change and sustainable practice.

Students as individuals gain from having an effective therapeutic skill set embedded in their relationships with teaching staff, which over time they learn to use more effectively on themselves and each other. This is also modelled by teaching staff, who are transparent in sharing how a solution orientated approach can guide and support through a range of challenging situations. Understanding the implications of emotional labour (Edward, Hercelinsky and Giandinoto 2017) and mutual support strategies are incorporated into the trigger situations explored together with students, so that professional abilities and interpersonal skills are scaffolded (Phumeechanya and Wannapiroon 2014) together at levels of increasing complexity through the learning experience (Box 1). We see SOL as aimed at both student and service-user well-being while having the potential to be embedded throughout the programme. 
Working together to find solutions has an extensive evidence base, but under-explored potential in health education. The solution orientated approach is more than problem-based learning reworded. Linguistic choices have deeply embedded emotional consequences that drive behaviour (Marrero et al 2017) so a deliberate and positive orientation to 'solutions' is designed to lead to optimism and commitment while the strategy itself provides a structured approach to achieving goals. Benefits of working together to solve problems include 'deeper learning' (Dolmans and Gijbels 2013), bridging the theory-practice gap (D'Sa and Bhaduri 2013), improved long term retention of content and improved clinical skills and reasoning (Prosser and Sze 2014). Emotional intelligence is enhanced through aiding students to work autonomously, feel competent and related to others, and be intrinsically motivated and selfregulating (Dolmans and Gijbels 2013, D’Sa and Bhaduri 2013). Students develop life-long learning skills (Prosser and Sze 2014), and essential soft skills including team working, communication and interpersonal skills (Cooper and Carver 2012). 'Solution Orientated Learning' is not well-known in health education, but has had positive outcomes in sustainability education where structured active experiential learning has empowered students in learning how to think, both strategically and ethically (Wiek and Kay 2015) with the focus on creative solution-finding.

Alignment of learning outcomes, teaching content and assessment are well established (Biggs and Tang 2011); in addition in the solution-orientated approach we model alignment of professional values and interpersonal approaches with those we hope students will demonstrate with service users. We take a person-centred approach, based on the work of Rogers (2004), aiming to relate to students with empathy, genuineness and unconditional positive regard. So we respond to classroom issues using skills drawn from professional practice, including those of person-centred counselling (Rogers 2004), solution-focused therapy (Shennan 2014) and motivational interviewing (Lundahl et al 2013).

Learning needs identified by student nurses primarily respond to the requirement to deliver safe effective person-centred care within a team-orientated approach. But in small group 
work, student nurses also learn to give and receive constructive criticism, to notice each other's signs of stress and to adjust and offer support so that they can work effectively together. They learn to learn, but also learn to teach, regularly sharing knowledge in seminars, presentations and small group work. Other examples of our SOL activities include working with experts by experience to explore the theory-practice link (Maher et al 2017) and working with actors to practice specialist communication skills for working with people living with dementia. Students practice articulating a point of view, listening to complex arguments, assertiveness and prioritisation skills, all of which benefit their ability to manage workloads and liaise with a range of colleagues.

In identifying and working towards solutions together, the students come to rely on each other and build strong friendships. Having a social network of trusted colleagues is essential in both building resilience (Burdick 2014) and promoting retention (Read 2014). In this way students can mutually contribute to one another's long-term professional well-being.

In more formal structured sessions aimed at employability, students reflect on their own anxieties, strengths and weaknesses as they approach qualification. They research strategies that will empower them in addressing their perceived difficulties, including those around delegation, team working, having difficult conversations, challenging others and negotiating compromises as they transition into practice and approach leadership roles.

While successful recruitment is essential for organisations, it is equally important to retain experienced staff. Nurses leave because of feelings of isolation, threatened burnout and feeling overwhelmed by the demands of their jobs (HEE 2014). Having confidence in one's ability to cope lessens anxieties and promotes feelings of autonomy, lessening stress (Cummings 2011). Therefore, solution orientated outcomes should target development of the interpersonal skills, problem-solving ability and self-esteem that facilitate the ability to respond positively to stressful situations, to manage emotions effectively, respond assertively to unrealistic or unsafe expectations and learn through adversity. 


\section{$\underline{\text { Recommendations }}$}

We argue that a model which aligns values, skills, and knowledge together in learning outcomes, with taught content that reflects student nurses' needs alongside those of service users, and assessment strategies that reinforce expectations of professional practical and emotional competence has potential for long term benefit in addressing student well-being and retention of qualified nurses.

We propose a student-centred Solution Orientated Learning model that reflects a collaborative approach to identifying learning goals and constructing the steps required to achieve them, based upon the principles and steps of SFBT:

- Identify a learning outcome: ask the 'miracle question' and generate discussion around ideal outcomes, the skills, abilities and experiences that will result

- Identify existing strengths based on scaling questions, exceptions and previous solutions

- Generate optimism by exploring small steps and Facilitate Learning through relationships based on Rogerian values and person-centred communication skills

- Provide a 'soft scaffold': support students as they work through the steps that contribute to achieving the desired solutions and learning while formally and informally using SFBT based techniques that will sustain the student as they embed the new learning in practice

- Future focus - explore how this learning is transferable and what new learning is required

\section{$\underline{\text { Conclusions }}$}

Further work is needed to develop and evaluate the SOL model for nurse education. There is an ethical and business case for incorporating long term resilience preparation into preregistration nursing courses using a SOL approach. Lesson plans can be adjusted to incorporate the interpersonal skills and group experiences that will benefit students' current 
emotional well-being while laying the foundations for confident, capable, supportive and sustainable post-qualification practice.

\section{References}

Biggs J, Tang C (2011) (4 ${ }^{\text {th }}$ Edition) Teaching for Quality Learning at University McGraw Hill. Maidenhead

Brennan E (2017). Towards resilience and wellbeing in nurses. British Journal of Nursing. 26, 1, 43-47.

Braunstein K, Grant A (2016). Approaching solutions or avoiding problems? The differential effects of approach and avoidance goals with solution-focused and problem-focused coaching questions. Coaching. 9, 93-109.

Brown P (2016) The invisible problem? Improving students' mental health. Higher Education Policy Institute, Oxford. http://www.hepi.ac.uk/wp-content/uploads/2016/09/STRICTLYEMBARGOED-UNTIL-22-SEPT-Hepi-Report-88-FINAL.pdf accessed 14.8.17

Burdick W (2014) Social networks (and more) are necessary for student and faculty resilience. Medical Education 49, 17-9.

Carod-Artal F, Vazquez-Cabrera C (2013) Burnout Syndrome in an International Setting. Chapter 2 in Bahrer-Kohler S (2013) Burnout for Experts: Prevention in the Context of Living and Working. Springer. New York.

Cummings $C$ (2011). What factors affect nursing retention in the acute care setting? Journal of Research in Nursing 16, 489-500.

Cooper C, Carver N (2012). Problem based learning in mental health nursing: The students' experience. International Journal of Mental Health Nursing, 21, 2, 175-183.

Dolmans D, Gijbels D (2013). Research on problem-based learning: future challenges. Medical Education, 47, 2, 214-218.

D'Sa J, Bhaduri A (2013). Acceptability of a Problem-Based Learning Approach in a Baccalaureate Nursing Programme- A Pilot Study. International Journal of Nursing Education, 5,1, 92

Edward K-L, Hercelinsky J, Giandinoto J-A (2017). Emotional labour in mental health nursing: An integrative systematic review. International Journal of Mental Health Nursing 26, 215-225.

Good Governance Institute (2015) The nursing journey: recruitment and retention file:///C:/Users/id105387/Downloads/The-nursing-journey-recruitment-and-retention.pdf accessed 14.8.17

Health Education England (2014) Growing Nursing Numbers. Literature review on nurses leaving the NHS. London. HEE.

Lundahl B, Moleni T, Burke B, et al (2013) Motivational interviewing in medical care settings: a systematic review and meta-analysis of randomized controlled trials Patient Educ. Couns., 93, 157-168 
Maher M, Bell L, Rivers-Downing N, Jenkins, C (2017) How a service-user educator can provide insight into the recovery experience Mental Health Practice 20, 6, 27-31

Prosser M, Sze D (2014). Problem-based learning: Student learning experiences and outcomes. Clinical Linguistics \& Phonetics, 28, 1-2, 131-142.

Marrero H, Beltran D, Gamez E et al (2017). Understanding approach and avoidance in verbal descriptions of everyday actions: An ERP study. Cognitive, Affective and Behavioral Neuroscience. 17, 612-624.

Milner J, Myers S (2017) Creative ideas for Solution Focused Practice Jessica Kingsley. London.

Phumeechanya, N, Wannapiroon P (2014). Design of Problem-based with Scaffolding Learning Activities in Ubiquitous Learning Environment to Develop Problem-solving Skills. Procedia - Social and Behavioral Sciences. 116, 4803-4808.

Read E (2014). Workplace social capital in nursing: an evolutionary concept analysis. Journal of Advanced Nursing 70, 997-1007.

Rogers C (2004) On Becoming a Person Constable and Robinson. London.

Royal College of Nursing (2012). Persistent challenges to providing quality care: an RCN report on the views and experiences of frontline nursing staff in care homes in England. RCN. London.

Shennan G (2014) Solution Focused practice: Effective communication to facilitate change Palgrave Macmillan. Basingstoke.

Unite Students (2016) Student resilience: Unite students insight report Bristol. Unite Students http://www.unitestudents.com/about-us/insightreport/2016-full-report accessed 14.8.17

Wiek A, Kay B (2015). Learning while transforming: solution-oriented learning for urban sustainability in Phoenix, Arizona. Current Opinion in Environmental Sustainability. 16, 29 36. 
Box 1.Learning communication skills for effective working relationships, an example from nurse education

Year 1: Gaining consent for personal care when a service user has dementia

\begin{tabular}{|l|l|}
\hline $\begin{array}{l}\text { Solution Focused Therapy } \\
\text { Intervention }\end{array}$ & Teaching Intervention - small group work \\
\hline $\begin{array}{l}\text { 'Miracle question' to identify } \\
\text { student-centred learning } \\
\text { outcome }\end{array}$ & $\begin{array}{l}\text { Teaching staff ask: 'so if you woke up tomorrow and a } \\
\text { miracle had happened, and you were excellent at } \\
\text { gaining consent with people with dementia, how would it } \\
\text { look like to someone watching? What would it feel like? } \\
\text { What little things would you/your mentor notice first?' }\end{array}$ \\
\hline $\begin{array}{l}\text { Scaling questions and coping } \\
\text { questions }\end{array}$ & $\begin{array}{l}\text { Teaching staff ask: 'so on a scale of 1 to 10, where are } \\
\text { you now in your ability to gain consent? Respond } \\
\text { accordingly, eg, so even though you haven't yet had } \\
\text { much experience, you're already developing the skills to } \\
\text { get to '5'. What are you doing to get there? How would } \\
\text { you get to '6'? }\end{array}$ \\
\hline $\begin{array}{l}\text { What were your previous } \\
\text { solutions? }\end{array}$ & $\begin{array}{l}\text { Students are asked to consider how they would feel if } \\
\text { someone came up and began a personal care task } \\
\text { without asking permission. How might they respond? } \\
\text { How would the student try to address this situation in } \\
\text { practice? Role play in pairs, eg. being reluctant to have } \\
\text { hair brushed and gaining consent }\end{array}$ \\
\hline $\begin{array}{l}\text { Looking for exceptions, } \\
\text { compliments, future orientated } \\
\text { questions, do more of what } \\
\text { works }\end{array}$ & $\begin{array}{l}\text { When did it go ok? What did you do, what skills did you } \\
\text { use? What positive feedback could you give and } \\
\text { receive? } \\
\text { Teaching staff model the approach, eg. 'I noticed that } \\
\text { even though your service-user looked angry, you stayed } \\
\text { friendly, calm and pleasant as you approached him' }\end{array}$ \\
\hline $\begin{array}{l}\text { What else do you } \\
\text { student/s)/teaching staff need } \\
\text { to know? }\end{array}$ & $\begin{array}{l}\text { What are your next steps for learning? How could you } \\
\text { build your expertise and support your colleagues to do } \\
\text { the same? }\end{array}$ \\
\hline
\end{tabular}

